\title{
Viscosity of a Standard Soda-Lime-Silica Glass
}

\author{
Albert Napolitano and Earl G. Hawkins
}

(May 11, 1964)

\begin{abstract}
The viscosity of a soda-lime-silica glass has been measured at the National Bureau of Standards and seven other laboratories. Determinations were made in the range of $10^{2}$ to $10^{15}$ poises. The rotating cylinder was used at the higher temperatures $\left(800\right.$ to $1450{ }^{\circ} \mathrm{C}$ ) and the fiber elongation method at the lower temperatures $\left(520\right.$ to $\left.658{ }^{\circ} \mathrm{C}\right)$. The results have been critically evaluated and the glass has been issued as Standard Sample No. 710. This glass is available from the National Bureau of Standards.
\end{abstract}

\section{Introduction}

As a part of a program of establishing standard samples of glasses, the National Bureau of Standards has obtained a large quantity of soda-lime-silica glass of uniform composition. The viscosity of this glass has been measured at the National Bureau of Standards and at seven other laboratories. ${ }^{1}$ "The results have been analyzed and tabulated in a "Certificate of Viscosity Values" and the glass (with certificate) has been issued as Standard Sample No. 710.

The soda-lime-silica glass was selected as the first of a series of standard glasses because it is relatively stable both in storage and at the temperatures at which viscosity measurements are made. Also it is of a composition close to that of commercial glasses that are made in the largest quantities.

A lead-silicate glass which is representative of another important commercial group of glasses has been selected as a second standard glass. This will soon be issued as a viscosity standard (No. 711). As a continuation of this program on standard glasses, other physical properties will be measured on these two glasses as well as on other glasses to be issued as standards.

\section{Sample}

Over the course of a number of years there have been several attempts by individual laboratories and by cooperative efforts among several laboratories to produce lots of glass that could be used for standards of viscosity and other physical properties. In spite of painstaking measurements of properties, these attempts were not completely successful and it has been generally concluded that the major reason has been that the lots of glass from which samples were taken were not sufficiently uniform

\footnotetext{
${ }_{1}^{1}$ List of participating laboratories which made viscosity and other propert measurements on Standard Sample No. 710:

Armstrong Cork Co., Lancaster, Pa.

Bausch \& Lomb, Inc., Rochester, N.Y.

Brockway Glass Co., Inc., Brockway, $\mathrm{Pa}$

Corning Glass Works, Corning, X.Y.

Emhart Manufacturing Co., Hartford, Conn.

General Electric Co., Cleveland, Ohio

Hazel-Atlas Glass Co., Plainfield, Ill.

Kimble Glass Div., Owens-Illinois, Vineland, N.J. (Lab. A).

National Bureau of Standards, Washington, D.

Owens-Corning Fiberglas Cor

University of Rochester, Rochester, N.Y.
}

for the purpose. With this background, every effort was made at the start of this work to obtain a quantity of glass that was as uniform as possible and to verify the uniformity before attempting to make viscosity measurements.

A contract was placed with a glass producer to furnish $900 \mathrm{~kg}$ of soda-lime-silica glass in equipment which is used for the continuous production of optical glass of instrument quality. It was specified that the entire lot was to be produced in one continuous operation, without changes in the batch composition. It was further specified that the index of refraction of the entire lot should be uniform within \pm 0.0001 after all samples had been given a uniform heat treatment. The supplier was able to comply with these stringent requirements except that no glass was supplied for three brief periods during the operation when the glass was apparently either off index or was discarded for other reasons.

The glass was made in the form of bars having a cross section of about $5 \mathrm{~cm}$ by $7.5 \mathrm{~cm}$. This was cut in lengths of 60 to $100 \mathrm{~cm}$. The bars were marked with the hour of manufacture to show the sequence of production.

When the glass was received the homogeneity was checked by measuring the index of refraction on specimens taken from about every $10 \mathrm{~kg}$ of glass. This corresponded to an average of two to three index samples for every hour of the production run. Samples were measured both in the condition as received and after they all had been given the same heat treatment. The results of these index measurements are shown in figure 1. Only one value is plotted for each hour for clarity. Index of refraction $\left(\mathrm{N}_{\mathrm{D}}\right.$-line) measurements were made on a Grauertype refractometer which is accurate to approximately $\pm 0.00002[1] .^{2}$

Uniformity of index is not an absolute check on uniformity of composition, since it is possible for glasses of widely different chemical composition to have the same index of refraction. However, considering the conditions under which this glass was made, that is, in a continuous operation with no deliberate changes in batch composition, it would require a most unusual set of circumstances to permit a significant change in composition that

2 Figures in brackets indicate the literature references at the end of this paper. 


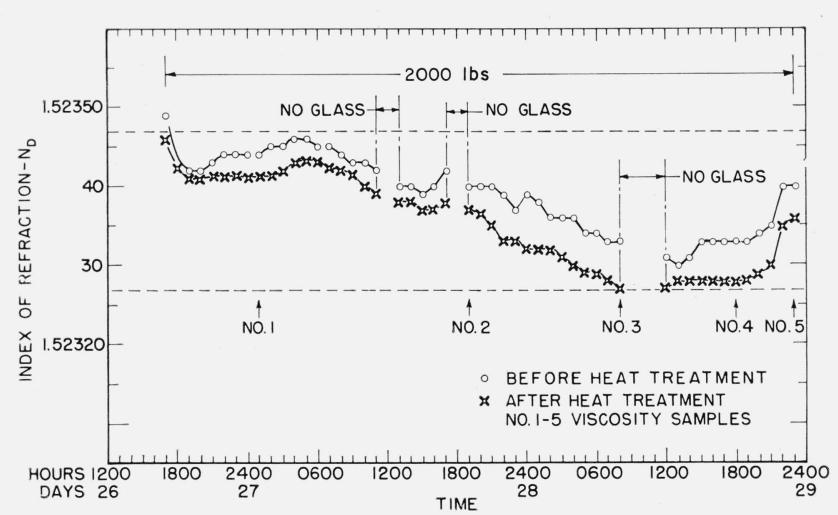

Figure 1. Index variation of Standard Glass No. 710.

would not be reflected by changes in index of refraction. The most likely causes of composition changes in the glass produced in a continuous type of melting operation would be changes in volatilization losses, refractory solution, or inadvertent changes in batch composition during the more than two days required to make the lot of glass.

The chemical composition of the glass as calculated from batch composition was as follows:

$\begin{array}{lr}\mathrm{SiO}_{2} & 70.5 \text { percent } \\ \mathrm{Na}_{2} \mathrm{O} & 8.7 \\ \mathrm{~K}_{2} \mathrm{O} & 7.7 \\ \mathrm{CaO} & 11.6 \\ \mathrm{Sb}_{2} \mathrm{O}_{3} & 1.1 \\ \mathrm{SO}_{3} & 0.2 \\ \mathrm{R}_{2} \mathrm{O}_{3} & 0.2\left(\mathrm{Fe}_{2} \mathrm{O}_{3}-0.02 \%\right)\end{array}$

Chemical analyses ${ }^{3}$ were made by four of the participating laboratories and their results indicate that the glass composition conforms closely to that given above. No attempt was made to analyze a large number of samples from the melt since it was believed that the chemical methods would not be sufficiently sensitive to reflect the small differences in composition that could be detected by measurements of index of refraction. In this composition range a change of approximately 0.06 percent in $\mathrm{Na}_{2} \mathrm{O}$ will change the index by 0.0001 [2].

As a further check on uniformity, measurements of viscosity were made on five samples taken from different positions in the lot of glass (fig. 1, Nos. 1, 2, 3, 4, and 5). Three of the samples, Nos. 2, 3, and 5 , were selected in regions where index of refraction showed the greatest rate of change. It will be seen later (table 4) that the uniformity of these samples was within specified limits. The details of these measurements are given in the section of this paper on Results.

\section{Apparatus and Method of Measurement}

The apparatus and methods used at the National Bureau of Standards for measuring viscosity are described in detail, those used by the cooperating

3 This glass is not intended as a standard for chemical analysis. laboratories are covered by brief descriptions or literature references. ${ }^{4}$

\subsection{High-Temperature Viscometer}

In the range of $10^{2}$ to $10^{6}$ poises the rotating concentric cylinder method was used to measure the viscosity. This method has been used by many earlier investigators in their studies on glass. The geometry of the apparatus was similar to that of Bockris and Lowe [3], Lillie [4], and Robinson and Peterson [5] except for a modification of method of measuring the torque on the spindle.

The platinum-wound resistance furnace, figure 2 consists of one main coil and two auxiliary coils. The main heating coil (inner core) was wound on a $7.6 \mathrm{~cm}$ (3 in.) i.d. alundum core $35.6 \mathrm{~cm}$ (14 in.) long with 80 percent $\mathrm{Pt}-20$ percent $\mathrm{Rh}$ resistance wire $0.081 \mathrm{~cm}$ (0.032 in.) diam and six turns per 2.54 $\mathrm{cm}$ (1 in.). The outer heating coils (outer core) were wound at each end of an alundum core $9.5 \mathrm{~cm}$ ( $3 \frac{3}{4}$ in.) i.d. and $35.6 \mathrm{~cm}$ (14 in.) long. Each coil consisted of 18 to 20 turns. There were separate controls for each winding.

The crucible was made of 1 -mm-thick platinum and was $5 \mathrm{~cm}$ diam and $10 \mathrm{~cm}$ high. The bob was $1.25 \mathrm{~cm}$ diam, $3.75 \mathrm{~cm}$ long with $45^{\circ}$ tapered ends, and was suspended by a hollow platinum spindle $0.635 \mathrm{~cm}$ diam and $29.5 \mathrm{~cm}$ long. The bore of the spindle, $0.3175 \mathrm{~cm}$ diam, extended into the center of the bob to accommodate a thermocouple for measuring the temperature of the glass before and after viscosity measurements.

The crucible was mounted and centered on a mullite pedestal which extended out through the bottom of the furnace and was attached to a turntable which was an integral part of the driving mechanism. The $25.0 \mathrm{~cm}$ pedestal was hollow and accommodated another thermocouple to read temperatures directly below the bottom of the crucible. A commercial insulation "Fiberfrax" which was used to pack the opening around the pedestal, offered no resistance to the rotation or vertical movement.

The complete driving mechanism was mounted on an elevator table which had $25.0 \mathrm{~cm}$ vertical travel. The drive consisted of an 1800-rpm, 1/8-hp synchronous motor connected to interchangeable gear reducers which gave a range of crucible speeds from $0.030288 \mathrm{rpm}$ to $1.3493 \mathrm{rpm}$.

The short (15-sec) term period of frequency stability of the power line had a mean error from 60 $\mathrm{c} / \mathrm{s}$ of 0.1 percent and a maximum error from $60 \mathrm{c} / \mathrm{s}$ of 0.2 percent. For a long $(30-\mathrm{min})$ term period the frequency stability had a mean error from $60 \mathrm{c} / \mathrm{s}$ of 0.038 percent and a maximum error from $60 \mathrm{c} / \mathrm{s}$ of 0.077 percent. This gave very good speed control on the outer crucible during viscosity measurements.

An electromagnetic torque balance [3] based on the principle of a large moving coil galvanometer was used to measure the torque by a null detection method.

4 The authors have gone into considerable detail on the design and construction of their apparatus because of the numerous inquiries they have received asking about this particular experimental setup. 


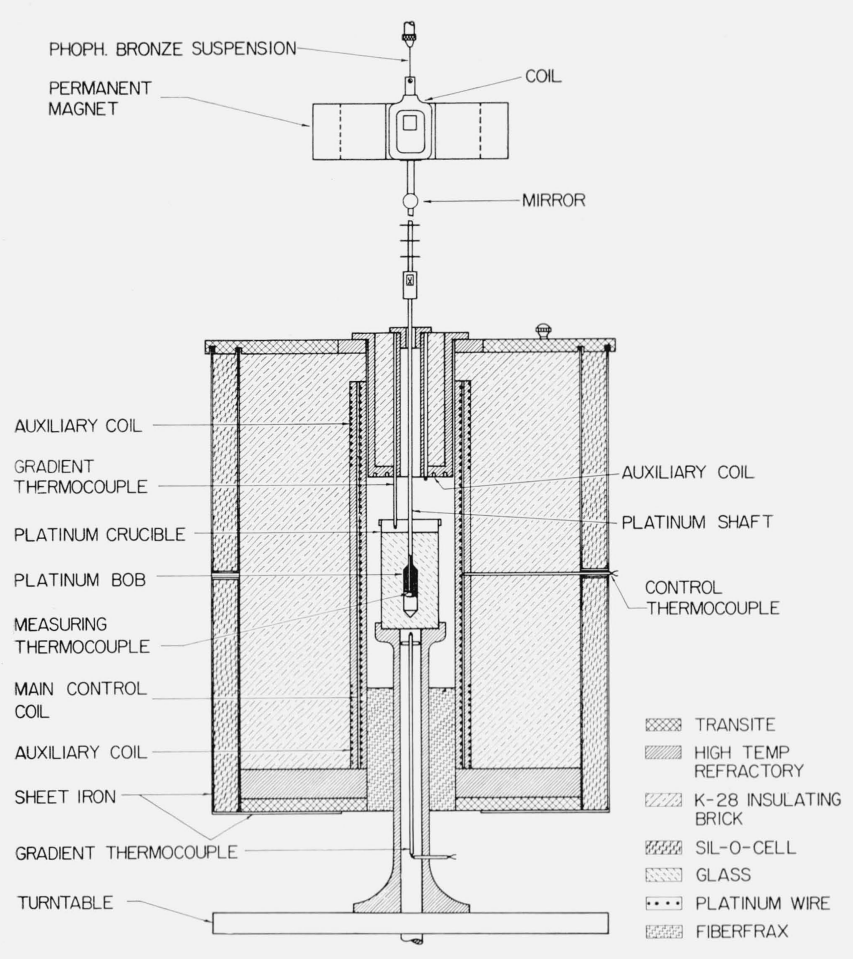

Figure 2. High-temperature viscosity furnace.

The galvanometer was made up of a permanent magnet Alnico II (sintered) with a 1650 gauss gap field strength and a coil which was an integral part of the suspension apparatus. The C-type magnet had a gap $4.76 \mathrm{~cm}$ wide, $4.76 \mathrm{~cm}$ high, and $3.81 \mathrm{~cm}$ deep. It was mounted on movable plates so that the magnet could be adjusted in any horizontal direction. The coil consisted of a rectangular aluminum frame with about $500 \mathrm{~m}$ of No. 34 insulated copper wire wound around it. The resistance of the coil was $425 \Omega$. In series with the coil were several resistors adjustable from $20,000 \Omega$ to $300,000 \Omega$, fixed resistors $1 \mathrm{M} \Omega$ to $10 \mathrm{M} \Omega$ and four standard fixed resistors $10 \Omega, 25 \Omega, 100 \Omega$, and $1000 \Omega$. Current in the coil was adjusted to set up a coupling force which was opposite to that set up by the rotating crucible. The balance was observed through a telescope on a $1-\mathrm{m}$-radius scale set $1 \mathrm{~m}$ distant from a reflecting mirror on the axis of the suspension shaft just below the coil. The amount of current through the coil was found by measuring the voltage across a standard resistor with a Type $\mathrm{K}$ potentiometer. Polarity in the circuit could be reversed to accommodate reversal of crucible rotation.

The coil of the suspension apparatus was connected to an adjustable head. The suspensions were $5 \mathrm{~cm}$ long and made of phosphor-bronze wire ranging in diameter from $0.020 \mathrm{~cm}$ to $0.0635 \mathrm{~cm}$, and were easily interchangeable to obtain sensitivity needed. The coil was connected to the platinum spindle by a brass rod which had a series of fins on it to radiate heat and a chuck to hold the platinum spindle of the bob.
The apparatus was calibrated at $25^{\circ} \mathrm{C}$ and $40{ }^{\circ} \mathrm{C}$ with NBS Standard oils. These oils ranged in viscosity from $1 \mathrm{P}$ to $500 \mathrm{P}$. Temperatures were measured with a calibrated copper-constatan thermocouple in the same way that they would be measured at higher temperatures with $\mathrm{Pt}-\mathrm{PtRh}$ thermocouples. Since molten glasses cover such a wide range of viscosities the calibration was checked at higher viscosities $\left(10^{2}\right.$ to $\left.10^{5} \mathrm{P}\right)$ with "abitol."

Calibration was carried out at a given level of liquid (oil) in the crucible and the bob immersed to $12 \mathrm{~mm}$ of the bottom of the crucible. These conditions of liquid level and depth of immersion were maintained at elevated temperatures, using molten glass, by adjusting the position of the crucible to allow for expansion of glass and the furnace components with increase in temperature. This amounted to lowering the crucible about $0.5 \mathrm{~mm}$ for every $100^{\circ} \mathrm{C}$ increase in temperature of measurement. The calibration was also corrected for the volume expansion of the platinum bob when used at the higher temperatures. This correction ranged from 2.5 to 4.5 percent depending on the temperature of measurement.

In making measurements at high temperatures, readings were taken on three thermocouples: one above the surface of the glass, one just below the crucible, and one inside the inner cylinder or bob. Once the two thermocouples above and below the glass read within $1{ }^{\circ} \mathrm{C}$, a reading was taken of the one inside the bob; torque measurements were made at various angular velocities in both directions, and then another reading of the thermocouples was taken. The leads to the thermocouples inside the bob and below the crucible were disconnected when the torque measurements were taken. The average of the two temperature readings, before and after, was taken as the viscosity temperature of measurement.

The current I required to counterbalance or zero the torque producing the deflection angle of the inner bob (in the rotating viscometer) is directly proportional to the viscosity $\eta$ of the test liquid and the angular velocity $\omega$ of the outer rotating crucible, i.e.,

$$
I=C \omega \eta
$$

where $C=$ constant of proportionality depending on the geometry of the apparatus.

Comparing the current $I_{2}$ of an unknown liquid with that of a "standard" or liquid of known viscosity, $I_{1}$, [6] one has

$$
\frac{I_{2}}{I_{1}}=\frac{\eta_{2} \omega_{2}}{\eta_{1} \omega_{1}}
$$

or

$$
\eta_{2}=\eta_{1} \frac{I_{2} \omega_{1}}{I_{1} \omega_{2}}
$$

\footnotetext{
${ }_{5}$ A sample (Lot AZK108) was obtained from Hercules Powder Co., Wilmington, Del., for experimental use only. This was measured, using a calibrated Hoeppler viscometer, at 30,40 , and $50^{\circ} \mathrm{C}$.
} 
where the subscripts 1 and 2 stand for the known and unknown liquids, respectively.

\subsection{Low-Temperature Viscosity}

Measurements of low-temperature viscosity were made by the fiber elongation method. This method has been developed by many investigators such as Lillie [4], Robinson and Peterson [5], Poole [7], Norton [8], and Boow and Turner [9]. The derivation of the equation used for determining the viscosity by this method is given by Lewis, Squires, and Broughton [10].

$$
\eta=\frac{F l}{3 A \frac{d l}{d t}}
$$

or as used in these calculations

$$
\eta=\frac{60 F l f}{3 A \frac{d l}{d t}}
$$

where:

$$
\begin{aligned}
F & =\text { extending force }(\mathrm{dyn}) \\
l & =\text { fiber length }(\mathrm{cm}) \\
A & =\text { fiber cross-section area }\left(\mathrm{cm}^{2}\right) \\
f & =\text { multiplying factor of optical lever } \\
\frac{1}{f} \frac{d l}{d t} & =\text { elongation rate }(\mathrm{cm} / \mathrm{min})
\end{aligned}
$$

The tube furnace used in these measurements was $50.8 \mathrm{~cm}$ (20 in.) high and $15.2 \mathrm{~cm}$ (6 in.) diam, figure 3. It was heated by three separately controlled windings of 80 percent $\mathrm{Pt}-20$ percent $\mathrm{Rh}$

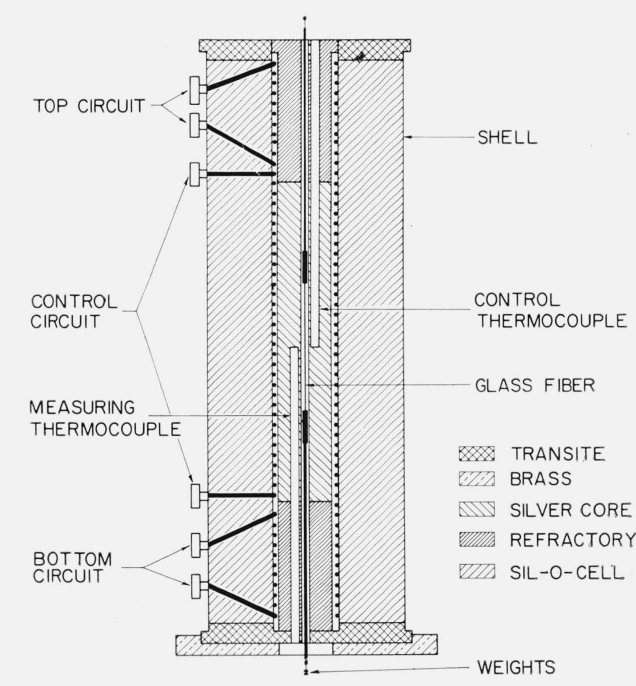

Figure 3. Low-temperature viscosity furnace. resistance wire wound on a $4.1 \mathrm{~cm}(1-5 / 8$ in.) i.d. alundum core. The inner silver core $25.4 \mathrm{~cm}$ (10 in.) long and $3.81 \mathrm{~cm}$ (1 $1 / 2 \mathrm{in}$.) diam had an inside bore $0.635 \mathrm{~cm}(1 / 4$ in.) diam to accommodate the fiber and also two off-center holes at the top and bottom to the midpoint of the core for thermocouples. The fiber was suspended by means of stainless steel rods and Inconel chucks.

The fibers used in these measurements were 0.5 to $1 \mathrm{~mm}$ in diameter, $10 \mathrm{~cm}$ long, and of uniform diameter throughout their length. All fibers were well-annealed and those that were used for determinations below the annealing temperature were "stabilized" for lengthy periods. Weights ranging from 5 to $1000 \mathrm{~g}$, depending on the temperature of test, were used to apply tension to the fibers. An optical lever with a multiplying factor of 50 was used to observe the elongation rates using a telescope equipped with a vertical scale.

\subsection{Participating Laboratories}

The methods used by the participating laboratories are given by literature reference and very brief notes in table 1. Calibration methods used by each participating laboratory (except Laboratory A) are not discussed here because it is assumed that each laboratory followed procedures given in their

\begin{tabular}{|c|c|c|}
\hline Lab. & High temperature & Low temperature \\
\hline$A^{*}$ & Rotating cylinder $[3,4] \ldots$ & Fiber elongation $[5,9]$ \\
\hline $\mathrm{B}^{*}$ & Rotating cylinder $[4] \ldots$ & Fiber elongation [7] \\
\hline $\mathrm{C}$ & $\begin{array}{l}\text { Rotating cylinder }[4] \\
\text { The inner cylinder was rotated and torque } \\
\text { measurements made with a Brookfield RVT } \\
\text { Viscometer Sillimanite crucibles used. }\end{array}$ & Fiber elongation [7] \\
\hline $\mathrm{D}^{*}$ & Rotating cylinder $[4] \ldots$ & Beam bending [12] \\
\hline $\mathrm{E}^{*}$ & $\begin{array}{l}\text { Rotating cylinder [5] } \\
\quad \text { Method of measuring deflection consisted of } \\
\text { a disk graduated in } 360^{\circ} \text { mounted directly on } \\
\text { the spindle shaft. }\end{array}$ & \\
\hline $\mathrm{F}^{*}$ & Rotating cylinder $[14] \ldots$ & \\
\hline $\mathrm{G}$ & $\begin{array}{l}\text { Rotating cylinder }[4,5] \\
\text { Furnace heated by eight globars placed sym- } \\
\text { metrically between a furnace lining and a } \\
\text { vertical refractory core }\end{array}$ & \\
\hline $\mathrm{H}$ & Rotating cylinder [4] & \\
\hline
\end{tabular}
literature references. These methods are essentially the same as Lillie [4] and Robinson and Peterson [5]. In the case of Laboratories C and F, a Brookfield $\mathrm{RV}$ T viscometer was used to make torque measurements.

TABLE 1. Methods used by participating laboratories

*Laboratories A, B, D, E, F, I, and J determined softening point following ASTM Procedure [11].

Laboratories A, D, E, I, and J determined annealing and strain point following ASTM Procedure [13].

\section{Results}

\subsection{Viscosity Measurements Made at NBS (Laboratory A)}

The lower temperature limit used in the analysis of the viscosity data was the annealing region 
(actually some $15{ }^{\circ} \mathrm{C}$ above the the annealing temperature, $546{ }^{\circ} \mathrm{C}$ ). Measurements taken below this temperature showed that the measured viscosity was dependent on the thermal history of the glass. This was first observed by Lillie [15] and subsequently by Otto [16].

The effect of thermal history on the fibers used in this study can be seem from table 2 and figure 5 . Viscosity measurements were made on fibers that received two different heat treatments. One group of fibers was measured at the test temperature in the state they were drawn, i.e., high "fictive temperature" [17]. The other group of fibers was heat-treated at the annealing temperature $\left(546{ }^{\circ} \mathrm{C}\right)$ for $1 \mathrm{hr}$ and then measured at the test temperature.

TABLE 2. Low-temperature viscosity of fibers of different thermal histories

\begin{tabular}{|c|c|c|c|c|c|}
\hline \multicolumn{3}{|c|}{ Stabilized fibers } & \multicolumn{3}{|c|}{ Annealed fibers } \\
\hline Temp. & $\log \eta$ & $\underset{\text { time }{ }^{1}}{\text { Holding }}$ & Temp. & $\log \eta$ & $\underset{\text { time }^{2}}{\text { Holding }}$ \\
\hline $\begin{array}{c}{ }^{\circ} \mathrm{C} \\
519.2 \\
538.4 \\
548.9 \\
556.6\end{array}$ & $\begin{array}{l}\text { 15. } 048 \\
13.804 \\
13.385 \\
12.968\end{array}$ & $\begin{array}{l}h r \\
265 \\
100 \\
65 \\
18\end{array}$ & $\begin{array}{l}{ }^{\circ} \mathrm{C} \\
519.5 \\
529.6 \\
538.7 \\
549.5 \\
558.3\end{array}$ & $\begin{array}{l}\text { 14. } 604 \\
\text { 14. } 072 \\
\text { 13. } 729 \\
13.201 \\
\text { 12. } 854\end{array}$ & $\begin{array}{r}h r \\
4 \\
2 \\
1 \\
1 \\
1\end{array}$ \\
\hline $\begin{array}{l}560.2 \\
565.7 \\
569.4 \\
571.6 \\
575.8 \\
580.4 \\
590.0 \\
600.1 \\
609.8 \\
618.7 \\
626.5 \\
628.4 \\
633.9 \\
639.6\end{array}$ & $\begin{array}{r}12.751 \\
12.480 \\
12.31 \\
12.203 \\
12.000 \\
11.804 \\
11.425 \\
11.066 \\
10.712 \\
10.436 \\
10.144 \\
10.067 \\
9.918 \\
9.734\end{array}$ & $\begin{array}{r}16 \\
16 \\
8 \\
2 \\
1 \\
1 / 2\end{array}$ & $\begin{array}{l}564.7 \\
574.6 \\
585.2\end{array}$ & $\begin{array}{l}\text { 12. } 485 \\
\text { 12. } 064 \\
11.645\end{array}$ & $\begin{array}{l}1 \\
1 \\
1\end{array}$ \\
\hline
\end{tabular}

1 Tlme held at indicated temperature before measurements of viscosity were made.

2 Time needed for furnace to reach thermal equilibrium at test temperature.

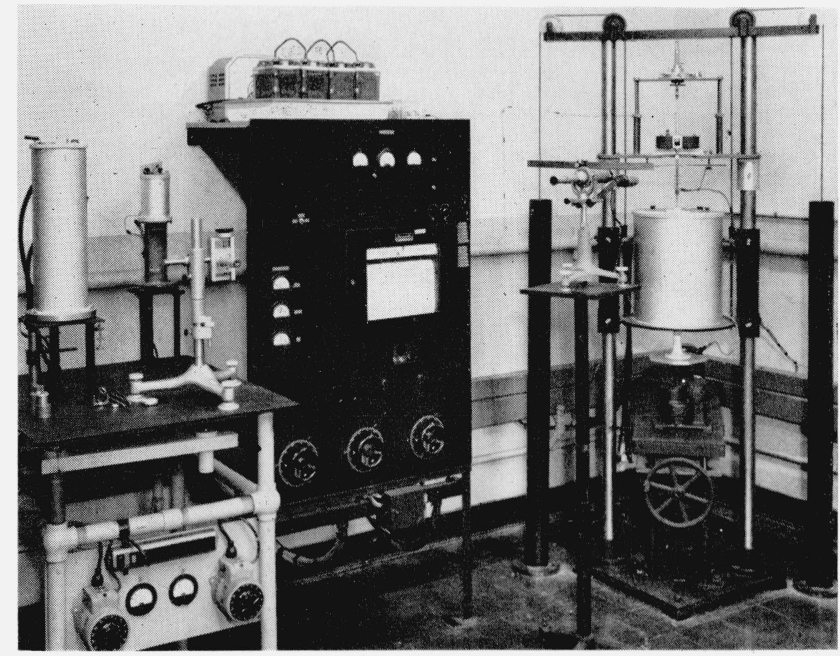

Figure 4. Laboratory setups of viscosity apparatus.
At approximately $560{ }^{\circ} \mathrm{C}$ and above, figure 5, all thermal history of the glass is erased in a very short time and the measured viscosity reflects the equilibrium state of the glass at the temperature of measurement. Measurements made at $560{ }^{\circ} \mathrm{C}$ after holding for $16 \mathrm{hr}$ or $1 \mathrm{hr}$ on fibers with two different thermal histories gave the same result.

The results of viscosity measurements on five samples selected from the lot of glass as indicated in figure 1 are given in table 3 . All of these measurements were made by laboratory A (NBS).

In order to derive a viscosity curve for each of the five glasses, the data points from both the low temperature fiber elongation method and the high temperature rotating cylinder method were combined and fitted to the Fulcher equation [18] by a least squares calculation. This equation ${ }^{6}$ has the form:

$$
\log _{10} \eta=A+\frac{B}{T-T_{0}}
$$

${ }_{6}^{6}$ The fit of viscosity-temperature data for glasses to the Fulcher equation has been shown by previous investigators to be exceptionally good. For ease of manipulation, interpolation, and examining dato for nonsystematic errors it has proven to ben, interpolation, and exaning data for nonsystematic errors it has proven to be very useful. The use of data points from both the low temperature comer elo will show that, in the range $10^{6}$ to $10^{10} \mathrm{P}$, the continuity of the two methods can will show that, in the range $10^{6}$ to $10^{10} \mathrm{P}$, the continuity of the two methods can be substantiated.

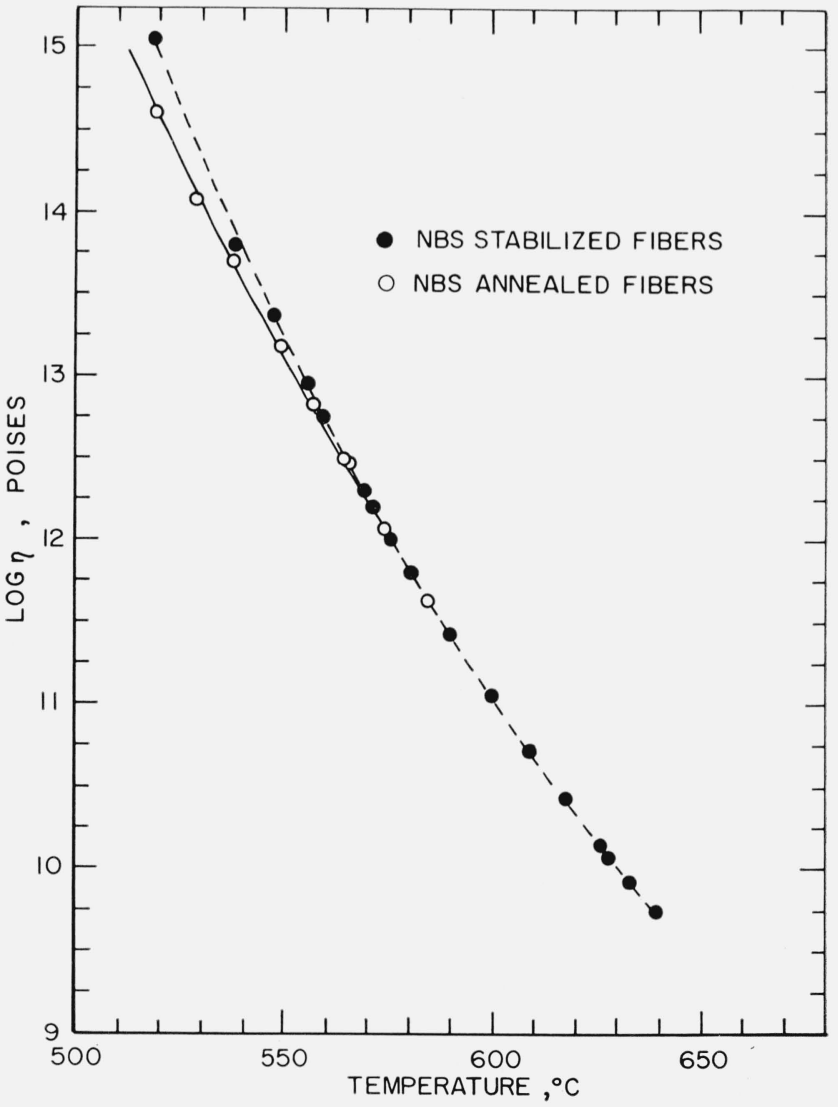

Figure 5. Viscosity of glass after different heat treatments. 
TABLE 3. Viscosities of five samples

\begin{tabular}{|c|c|c|c|c|c|c|c|c|c|c|}
\hline \multicolumn{2}{|c|}{ Sample No. 1} & \multicolumn{2}{|c|}{ Sample No. 2} & \multicolumn{2}{|c|}{ Sample No. 3} & \multicolumn{2}{|c|}{ Sample No. 4} & \multicolumn{2}{|c|}{ Sample No. 5} & \multirow{2}{*}{$\begin{array}{l}\text { Test } \\
\text { method }\end{array}$} \\
\hline Temp & Log $\eta_{\mathrm{obs}}$ & Temp & $\log \eta_{\mathrm{obs}}$ & Temp & Log $\eta_{\text {obs }}$ & Temp & Log $\eta_{\text {obs }}$ & Temp & $\log \eta_{\mathrm{obs}}$ & \\
\hline $\begin{array}{c}{ }^{\circ} \mathrm{C} \\
560.2 \\
600.1 \\
639.6\end{array}$ & $\begin{array}{r}12.751 \\
11.066 \\
9.734\end{array}$ & $\begin{array}{l}{ }^{\circ} \mathrm{C} \\
565.7 \\
590.0 \\
626.5\end{array}$ & $\begin{array}{l}12.480 \\
11.425 \\
10.144\end{array}$ & $\begin{array}{c}{ }^{\circ} \mathrm{C} \\
574.6 \\
585.2 \\
628.4\end{array}$ & $\begin{array}{l}12.064 \\
11.645 \\
10.067\end{array}$ & $\begin{array}{c}{ }^{\circ} \mathrm{C} \\
575.8 \\
609.8\end{array}$ & $\begin{array}{l}12.000 \\
10.712\end{array}$ & $\begin{array}{l}{ }^{\circ} \mathrm{C} \\
580.4 \\
618.7 \\
633.9\end{array}$ & $\begin{array}{r}11.804 \\
10.436 \\
9.918\end{array}$ & $\left\{\begin{array}{c}\text { Fiber elon- } \\
\text { gation. }\end{array}\right.$ \\
\hline $\begin{array}{r}855.1 \\
881.4 \\
901.4 \\
907.4 \\
946.8 \\
1000.4 \\
1102.9 \\
1112.4 \\
1202.5 \\
1306.1 \\
1306.7 \\
1412.3\end{array}$ & $\begin{array}{l}\text { 5. } 561 \\
5.255 \\
5.032 \\
4.997 \\
4.598 \\
4.136 \\
3.433 \\
3.373 \\
2.899 \\
2.435 \\
2.445 \\
\text { 2. } 060\end{array}$ & $\begin{array}{r}905.1 \\
1025.3 \\
1124.6 \\
1198.5 \\
1248.0 \\
1315.6 \\
1411.1\end{array}$ & $\begin{array}{l}\text { 4. } 999 \\
3.950 \\
3.295 \\
2.923 \\
2.690 \\
2.416 \\
2.082\end{array}$ & $\begin{array}{r}900.3 \\
945.7 \\
1019.1 \\
1054.6 \\
1103.5 \\
1200.6 \\
1212.0 \\
1298.4 \\
1402.4\end{array}$ & $\begin{array}{l}5.045 \\
4.601 \\
4.015 \\
3.751 \\
3.428 \\
2.912 \\
2.853 \\
2.475 \\
2.111\end{array}$ & $\begin{array}{r}904.7 \\
963.4 \\
996.5 \\
1103.1 \\
1123.0 \\
1214.8 \\
1315.7 \\
1414.5\end{array}$ & $\begin{array}{l}5.030 \\
4.441 \\
4.163 \\
3.437 \\
3.316 \\
2.853 \\
2.437 \\
2.074\end{array}$ & $\begin{array}{r}903.0 \\
954.4 \\
963.5 \\
1054.8 \\
1104.5 \\
1149.9 \\
1194.3 \\
1250.4 \\
1250.8 \\
1338.5 \\
1399.8 \\
1402.7\end{array}$ & $\begin{array}{l}4.999 \\
4.557 \\
4.411 \\
3.739 \\
3.430 \\
3.164 \\
2.947 \\
2.681 \\
2.684 \\
2.311 \\
2.105 \\
2.082\end{array}$ & $\left\{\begin{array}{l}\text { Rotating } \\
\text { cylinder }\end{array}\right.$ \\
\hline
\end{tabular}

where $\mathrm{T}=$ temperature in ${ }^{\circ} \mathrm{C}$

$$
\eta=\text { viscosity in poises }
$$

and $A, B$, and $T_{0}$ are constants.

The values of the parameters and of temperatures for specified viscosities calculated therefrom for each of the five samples are given respectively in tables 4 and 5 . In table 5 it is noted that the temperatures for the five samples at certain viscosity values are reproducible to well within $1{ }^{\circ} \mathrm{C}$. Due to this reproducibility temperatures throughout this paper are given to the nearest $0.1{ }^{\circ} \mathrm{C}$ for Laboratory $\mathrm{A}$ as well as for the participating laboratories. Even though all precautions were taken to eliminate temperature gradients in this work it is conceivable that they are still significant in these measurements. The data points from these five samples were also combined and treated as one sample to give one curve to represent the viscosity for the entire lot of glass. The constants for this equation are given on the bottom line of table 4 .

Table 6 gives the viscosity values along with their standard deviation (from the Fulcher equation) for each of the five glasses for $T=1300{ }^{\circ} \mathrm{C}$ and $T=600$ ${ }^{\circ} \mathrm{C}$. The values from the Fulcher equation using the combined data points from all five glasses are also shown in table 6 .

TABLE 4. Fulcher equation constants (five samples)

\begin{tabular}{|c|c|c|c|}
\hline Sample No. & $A$ & $B$ & $T_{0}$ \\
\hline 1. & -1.655 & 4266 & 264.5 \\
\hline $2 \ldots$ & -1.596 & 4204 & 267.4 \\
\hline $3 \ldots$ & -1.593 & 4202 & 267.6 \\
\hline $4 \ldots$ & -1.579 & 4195 & 267.6 \\
\hline $5_{-.}$ & -1.649 & 4258 & 265.1 \\
\hline Combined 1-5 & -1.626 & 4239 & 265.7 \\
\hline
\end{tabular}

TавLE 5. Comparison of temperatures corresponding to specified viscosities calculated from the Fulcher equation parameters for each sample

\begin{tabular}{|c|c|c|c|c|c|c|}
\hline \multirow{2}{*}{$\log \eta$} & \multicolumn{6}{|c|}{ Temperature, ${ }^{\circ} \mathrm{C}$} \\
\hline & $\begin{array}{c}\text { Sample } \\
\text { No. } 1\end{array}$ & $\begin{array}{l}\text { Sample } \\
\text { No. } 2\end{array}$ & $\begin{array}{c}\text { Sample } \\
\text { No. } 3\end{array}$ & $\begin{array}{l}\text { Sample } \\
\text { No. } 4\end{array}$ & $\begin{array}{c}\text { Sample } \\
\text { No. } 5\end{array}$ & $\begin{array}{l}\text { Combined } \\
\text { No. } 1-5\end{array}$ \\
\hline 2.1 & 1400.5 & 1404. 9 & 1405.3 & 1407.8 & 1400.8 & 1403. 3 \\
\hline 2.5 & 1291.1 & 1293. 8 & 1294.1 & 1296. 0 & 1291.3 & 1293. 0 \\
\hline 3. 0 & 1180.8 & 1182.2 & 1182.4 & 1183.7 & 1181.0 & 1182. 0 \\
\hline 3.5 & 1092. 0 & 1092.4 & 1092.6 & 1093. 5 & 1092.0 & 1092.6 \\
\hline 4.0 & 1018.8 & 1018. 7 & 1018.8 & 1019.5 & 1018.8 & 1019.1 \\
\hline 4.5 & 957.5 & 957.1 & 957.2 & 957.6 & 957.5 & 957.6 \\
\hline $\begin{array}{l}\text { f. } \\
5.0\end{array}$ & 905.5 & 904.8 & 904.9 & 905.2 & 905.5 & $\begin{array}{l}90.0 \\
905.4\end{array}$ \\
\hline $\begin{array}{l}0.0 \\
5.5\end{array}$ & 860.7 & $\begin{array}{l}950.8 \\
859.9\end{array}$ & $\begin{array}{l}904.9 \\
859.9\end{array}$ & 860.2 & $\begin{array}{l}900.0 \\
860.7\end{array}$ & $\begin{array}{l}800.4 \\
860.5\end{array}$ \\
\hline 6.0 & 821.7 & $\begin{array}{l}820.9 \\
820.9\end{array}$ & $\begin{array}{l}80.9 .9 \\
820.9\end{array}$ & 821.1 & 821.8 & $\begin{array}{l}821.5 \\
821.5\end{array}$ \\
\hline $\begin{array}{l}0.0 \\
7.0\end{array}$ & 757.3 & $\begin{array}{l}820.9 \\
756.5\end{array}$ & $\begin{array}{l}820.9 \\
756.5\end{array}$ & $\begin{array}{l}821.1 \\
756.6\end{array}$ & $\begin{array}{l}821.8 \\
757.4\end{array}$ & $\begin{array}{l}821.0 \\
757.1\end{array}$ \\
\hline 8.0 & 706.3 & 705.5 & $\begin{array}{l}700.5 \\
705.6\end{array}$ & $\begin{array}{l}100.0 \\
705.5\end{array}$ & 706.4 & 706.0 \\
\hline $\begin{array}{l}8.0 \\
9.0\end{array}$ & 664.8 & $\begin{array}{l}004.5 \\
664.2\end{array}$ & $\begin{array}{l}0.00 \\
664.2\end{array}$ & $\begin{array}{l}06.5 \\
664.1\end{array}$ & 664.9 & $\begin{array}{l}060.0 \\
664.6\end{array}$ \\
\hline 10.0 & 630.5 & 630.0 & 630.0 & 629.9 & 630.6 & 630.3 \\
\hline 11.0 & 601.6 & 601.2 & 601.2 & 601.1 & 601.8 & 601.4 \\
\hline 12.0 & 576.9 & 576.6 & 576.7 & 576.5 & 577.1 & 576.8 \\
\hline
\end{tabular}

TABLE 6. Comparison of values of $\log \eta$ and standard deviations calculated for two specified temperatures from the data of the participating laboratories

\begin{tabular}{|c|c|c|c|c|c|}
\hline Lab. & $T=1300{ }^{\circ} \mathrm{C}$ & $\sigma$ & Lab. & $T=600{ }^{\circ} \mathrm{C}$ & $\sigma$ \\
\hline $\begin{array}{l}\text { A-No. } 1 \\
\quad \text { No. } 2 \\
\text { No. } 3 \\
\text { No. } 4 \\
\quad \text { No. } 5 \\
\text { Comb. 1-5 } \\
\text { B } \\
\text { C } \\
\text { D } \\
\text { E } \\
\text { F } \\
\text { G } \\
\text { H } \\
\text { Comb. A-H } \\
\text { Comb. A-E }\end{array}$ & $\begin{array}{l}2.465 \\
2.475 \\
2.476 \\
2.484 \\
2.465 \\
2.472 \\
2.469 \\
2.467 \\
2.468 \\
2.464 \\
2.541 \\
2.514 \\
2.534 \\
2.487 \\
2.471\end{array}$ & $\begin{array}{l}0.005 \\
.002 \\
.005 \\
.009 \\
.010 \\
.010 \\
.004 \\
.003 \\
.005 \\
.002 \\
.003 \\
.005 \\
.009 \\
.027 \\
.003\end{array}$ & $\begin{array}{r}\text { A-No. } 1 \\
\text { No. } 2 \\
\text { No. } 3 \\
\text { No. } 4 \\
\text { No. } 5 \\
\text { Comb. } 1-5 \\
\text { B } \\
\end{array}$ & $\begin{array}{l}11.060 \\
11.044 \\
11.048 \\
11.041 \\
11.065 \\
11.054 \\
11.071 \\
11.075\end{array}$ & $\begin{array}{r}0.016 \\
.022 \\
.020 \\
.032 \\
.041 \\
.029 \\
.048 \\
.001\end{array}$ \\
\hline
\end{tabular}

The following two conclusions are clear from table 6 :

(1) For both temperatures $\left(1300\right.$ and $600{ }^{\circ} \mathrm{C}$ ) the values of viscosity for each individual sample may be said to agree with the corresponding values from the combined equation (based on all five samples) using plus or minus one standard deviation from the individual sample and from the combined equation as the test of agreement. Thus, the combined 
equation represents to within its uncertainty [19] the viscosity of any of the five constituent samples, and also, it is assumed, of any other sample from this lot. It is recalled, figure 1 , that these samples were chosen in the least favorable case for uniformity.

(2) The uncertainty of the viscosity as given by the standard deviation is a function of temperature, the precision at the higher temperature being better by a factor of about three. This is due to the well established fact that the rotating cylinder method is more precise than the methods which are used at low temperatures. This was the reason for the choice of the representative temperatures 1300 and $600{ }^{\circ} \mathrm{C}$.

\subsection{Viscosity Measurements Made at Participating Laboratories}

One sample from the lot of glass was sent to each of 10 cooperating laboratories to determine highand low-temperature viscosity for comparison with each other and with Laboratory $\mathrm{A}$. In addition they were asked to determine the softening, annealing, and strain points using standard ASTM procedures $[11,13]$. These results were also compared with similar determinations made in Laboratory $\mathrm{A}$.
The results of the viscosity measurements from all of these laboratories are listed in table 7 . It is seen from table 7 that only two laboratories made both high- and low-temperature viscosity measurements.

The data points submitted by each laboratory were fitted to the Fulcher equation by the standard least square technique in the same manner as that used for Laboratory A. The values of the constants so obtained for $A, B$, and $T_{0}$, for all laboratories (including Laboratory $A$ ) are shown in table 8 in the range of temperatures in which viscosity measurements were actually made. A comparison of the data from each laboratory is shown in table 9 . Temperatures at specified values of $\log$ viscosity were calculated using those constants derived from each laboratory's data.

The data points from the seven participating laboratories shown in table 7 and those from the five samples of Laboratory A were combined and fitted to the Fulcher equation. This gave:

$$
\log \eta=-1.568+\frac{4181}{T^{\circ} \mathrm{C}-268.9} .
$$

$\mathrm{T}_{\mathrm{ABLE}}$ 7. Experimental results of participating laboratories

\begin{tabular}{|c|c|c|c|c|c|c|c|c|c|c|c|c|c|c|}
\hline \multicolumn{2}{|c|}{ Lab. B } & \multicolumn{2}{|c|}{ Lab. C } & \multicolumn{2}{|c|}{ Lab. D } & \multicolumn{2}{|c|}{ Lab. E } & \multicolumn{2}{|c|}{ Lab. F } & \multicolumn{2}{|c|}{ Lab. G } & \multicolumn{2}{|c|}{ Lab. H } & \multirow{2}{*}{$\begin{array}{l}\text { Test } \\
\text { method }\end{array}$} \\
\hline Temp & $\log \eta_{\text {obs }}$ & Temp & $\log \eta_{\text {obs }}$ & Temp & $\log \eta_{\mathrm{obs}}$ & Temp & $\log \eta_{\mathrm{obs}}$ & Temp & $\log \eta_{\text {obe }}$ & Temp & $\log \eta_{\text {obs }}$ & Temp & $\log \eta_{\text {obs }}$ & \\
\hline $\begin{array}{r}{ }^{\circ} C \\
\text { a } 534.9 \\
551.7 \\
560.2 \\
582.2 \\
612.8 \\
662.2 \\
\\
1014.4 \\
1042.2 \\
1093.3 \\
1153.3 \\
1204.4 \\
1256.6 \\
1309.4\end{array}$ & $\begin{array}{r}13.976 \\
13.159 \\
12.720 \\
11.761 \\
10.615 \\
9.159 \\
\\
4.035 \\
3.827 \\
3.491 \\
3.151 \\
2.890 \\
2.656 \\
2.436\end{array}$ & $\begin{array}{r}\text { b } 584.5 \\
1098.5 \\
1158.0 \\
1183.7 \\
1216.0 \\
1282.5\end{array}$ & $\begin{array}{l}11.680 \\
3.478 \\
3.131 \\
3.000 \\
2.835 \\
2.539\end{array}$ & $\begin{array}{r}803.8 \\
844.4 \\
878.6 \\
930.8 \\
960.3 \\
998.1 \\
1040.4 \\
1080.6 \\
1117.1 \\
1157.2 \\
1192.1 \\
1230.2 \\
1272.0 \\
1308.9 \\
1353.1\end{array}$ & $\begin{array}{l}6.217 \\
5.659 \\
5.257 \\
4.719 \\
4.449 \\
4.132 \\
3.828 \\
3.562 \\
3.342 \\
3.121 \\
2.949 \\
2.764 \\
2.584 \\
2.435 \\
2.266\end{array}$ & $\begin{array}{r}802.0 \\
852.0 \\
900.0 \\
950.0 \\
1001.0 \\
1048.0 \\
1101.0 \\
1151.0 \\
1199.0 \\
1249.0 \\
1288.0\end{array}$ & $\begin{array}{l}6.339 \\
5.650 \\
5.077 \\
4.587 \\
4.170 \\
3.792 \\
3.436 \\
3.158 \\
2.909 \\
2.682 \\
2.513\end{array}$ & $\begin{array}{l}1025.6 \\
1063.9 \\
1103.3 \\
1147.8 \\
1196.1 \\
1248.9 \\
1309.4 \\
1378.9 \\
1456.1\end{array}$ & $\begin{array}{l}4.000 \\
3.750 \\
3.500 \\
3.250 \\
3.000 \\
2.750 \\
2.500 \\
2.250 \\
2.000\end{array}$ & $\begin{array}{r}790.0 \\
886.0 \\
983.0 \\
1088.0 \\
1290.0 \\
1335.0\end{array}$ & $\begin{array}{l}6.400 \\
5.220 \\
4.270 \\
3.540 \\
2.560 \\
2.380 \\
\end{array}$ & $\begin{array}{r}840.0 \\
848.0 \\
928.0 \\
1077.0 \\
1095.0 \\
1145.0 \\
1251.0 \\
1304.0 \\
1313.0\end{array}$ & $\begin{array}{l}5.775 \\
5.670 \\
4.787 \\
3.623 \\
3.518 \\
3.219 \\
2.715 \\
2.525 \\
2.487 \\
\end{array}$ & $\begin{array}{l}\text { Fiber } \\
\text { elongation. }\end{array}$ \\
\hline
\end{tabular}

a Lab. B-Holding times were respectively reading downward $119 \mathrm{hr}, 195 \mathrm{hr}, 39 \mathrm{hr}, 15 \mathrm{~min}, 10 \mathrm{~min}$, and $5 \mathrm{~min}$.

b Lab. C-Holding time not given.

TABLE 8. Fulcher equation constants from the data submitted by each participating laboratory

\begin{tabular}{|c|c|c|c|c|}
\hline Laboratory & Range & A & B & $\mathrm{T}_{0}$ \\
\hline $\begin{array}{l}\mathrm{A}\left({ }^{1}\right) \\
\mathrm{B} \\
\mathrm{C} \\
\mathrm{D} \\
\mathrm{E} \\
\mathrm{F} \\
\mathrm{G} \\
\mathrm{H} \\
\text { Gen. eq }{ }^{(2)}\end{array}$ & $\begin{array}{l}{ }^{\circ} C \\
560-1400 \\
560-1300 \\
580-1300 \\
800-1350 \\
800-1300 \\
1025-1450 \\
790-1340 \\
840-1310 \\
560-1450\end{array}$ & $\begin{array}{l}-1.626 \\
-1.655 \\
-1.761 \\
-1.584 \\
-1.586 \\
-1.727 \\
-1.473 \\
-1.211 \\
-1.626\end{array}$ & $\begin{array}{l}4,239 \\
4,271 \\
4,413 \\
4,186 \\
4,124 \\
4,580 \\
4,112 \\
3,711 \\
4,236\end{array}$ & $\begin{array}{l}265.7 \\
264.4 \\
256.2 \\
266.9 \\
281.8 \\
226.8 \\
268.7 \\
309.0 \\
266.0\end{array}$ \\
\hline
\end{tabular}

1 Data from samples $1-5$ combined.

Data from Laboratories A-E combined-see text.
Following the same procedure as was done for the five samples from Laboratory $A$, the values of $\log \eta$ along with their standard deviation for $T=1300{ }^{\circ} \mathrm{C}$ and $T=600{ }^{\circ} \mathrm{C}$ were calculated and are shown in table 6 . The values using the combined data of Laboratories A through $\mathrm{H}$ are also shown in table 6 .

It can be seen from table 6 that the values of viscosity at $1300{ }^{\circ} \mathrm{C}$, plus or minus their standard deviation, for Laboratories F, G, and $\mathrm{H}$ fall outside the viscosity value, plus or minus its standard deviation, from the combined data points of Laboratories A through H. If the data points from only Labora- 
TABLE 9.-Comparison of temperatures for specified viscosities calculated from appropriate Fulcher equation parameters (see table 8)

\begin{tabular}{|c|c|c|c|c|c|c|c|c|c|}
\hline \multirow{3}{*}{ Log viscosity } & \multicolumn{8}{|c|}{ Temperature, ${ }^{\circ} \mathrm{C}$} & \multirow{3}{*}{$\begin{array}{l}\text { Value from } \\
\text { combined } \\
\text { equation }\end{array}$} \\
\hline & \multicolumn{8}{|c|}{ Laboratories } & \\
\hline & $A^{1}$ & B & $\mathrm{C}$ & $\mathrm{D}$ & $\mathrm{E}$ & F & G & $\mathrm{H}$ & \\
\hline$P$ & & & & & & & & & \\
\hline $\begin{array}{l}2.00 \\
2.10\end{array}$ & & & & & & 1455. 7 & & & 1434.3 \\
\hline $\begin{array}{l}2.10 \\
2.25\end{array}$ & $\begin{array}{l}140.3 \\
1359.3\end{array}$ & & & 1358.7 & & $\begin{array}{l}1423.6 \\
1378.5\end{array}$ & & & $\begin{array}{l}1402.9 \\
1358.9\end{array}$ \\
\hline 2. 50 & 1293.0 & 1292.4 & 1297.3 & 1291.9 & 1291.0 & 1310.4 & 1303.7 & 1308.9 & 1292.7 \\
\hline 2.75 & $\begin{array}{l}129.0 \\
1234.3\end{array}$ & $\begin{array}{l}129.4 \\
1234.1\end{array}$ & 1236.4 & 1232.8 & 1232.8 & $\begin{array}{l}1010.4 \\
1249.9\end{array}$ & 1242.4 & 1245.8 & 1234.0 \\
\hline 3. 00 & 1182.0 & 1182.0 & $\begin{array}{l}1200.4 \\
1182.4\end{array}$ & 1180.1 & 1181.0 & 1195.7 & 1188.0 & $\begin{array}{r}1190.0 \\
1190.2\end{array}$ & 1181.7 \\
\hline 3. 50 & 1092.6 & 1093.0 & 1090.7 & 1090.3 & 1092.6 & 1103.1 & 1095. 6 & 1096. 6 & 1092.4 \\
\hline 4.00 & 1019.1 & 1019.7 & 1016. 0 & 1016.5 & 1020.0 & 1026.6 & 1020.0 & 1021.1 & $\begin{array}{l}1019.0 \\
\end{array}$ \\
\hline $\begin{array}{l}\text { 4. } \\
4.50\end{array}$ & $\begin{array}{r}1019.1 \\
957.6\end{array}$ & 958.4 & $\begin{array}{r}1010.0 \\
953.8\end{array}$ & $\begin{array}{r}1010.0 \\
954.9\end{array}$ & $\begin{array}{r}1020.0 \\
959.4\end{array}$ & 1020.0 & $\begin{array}{r}1020.0 \\
957.1\end{array}$ & $\begin{array}{r}1021.1 \\
958.7\end{array}$ & $\begin{array}{r}109.0 \\
957.5\end{array}$ \\
\hline 5. 00 & 905.4 & 906.2 & 901.3 & 902.6 & 907.9 & & 904.0 & 906.4 & 905.3 \\
\hline 5. 50 & 860.5 & 861.4 & 856.4 & 857.8 & 863.7 & & 858.4 & 861.9 & 860.5 \\
\hline 6. 00 & 821.5 & 822.4 & 817.5 & 818.8 & 825.4 & & 819.0 & 823.6 & 821.5 \\
\hline 6. 50 & 787.3 & 788.2 & 783.5 & 784.7 & 791.8 & & & & 787.3 \\
\hline 7. 00 & 757.1 & 757.9 & 753.6 & & & & & & 757.1 \\
\hline 8. 00 & 706.0 & 706.8 & 703.2 & & & & & & 706.1 \\
\hline 9.00 & 664.6 & 665.3 & 662.5 & & & & & & 664.7 \\
\hline 10. 00 & 630.3 & 630.9 & 628. 9 & & & & & & 630.4 \\
\hline 11.00 & 601.4 & 601.9 & 600.7 & & & & & & 601.5 \\
\hline 12.00 & 576.8 & 577.2 & 576.7 & & & & & & 576.9 \\
\hline
\end{tabular}

1 Results from Lab. A are the combined results from five samples.

tories A through E are combined and fitted to the Fulcher equation, one obtains :

$$
\log \eta=-1.626+\frac{4,236}{T^{\circ} \mathrm{C}-266} .
$$

The values of viscosity at 1300 and $600{ }^{\circ} \mathrm{C}$ along with their standard deviations from this equation are also given in table 6 . In the last column of table 9 the temperatures at specified values of viscosity are given for the combined data from Laboratories A through E.

In figure 6 , the calculated viscosities, represented by a horizontal line at zero ordinate, are based on the Fulcher equation computed from the data of Laboratories A through $\mathrm{E}$. The differences in the observed and calculated viscosities of each laboratory's data using this equation are plotted in figure 6 to show the

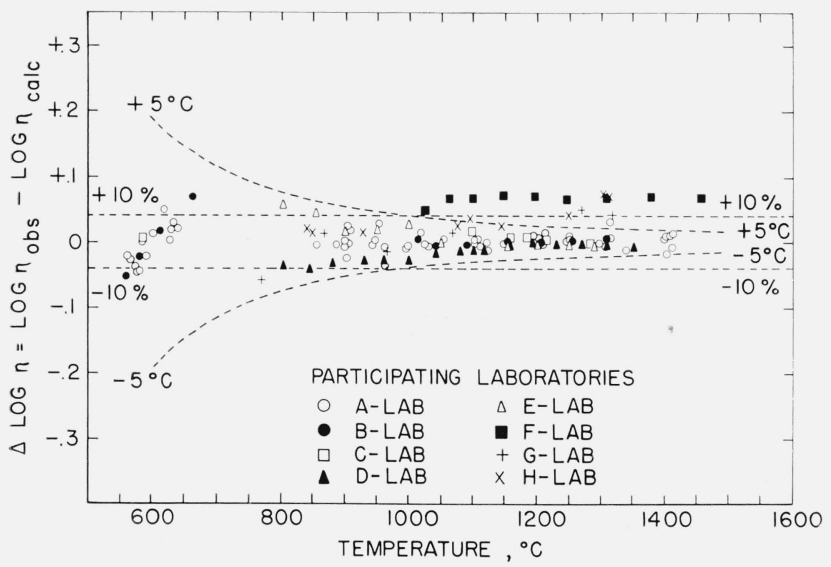

Figure 6. Differences in observed and calculated viscosities of participating laboratories on Standard Glass No. 710. scatter in these measurements. Closer inspection of figure 6 and table 9 shows that part of the data points submitted by Laboratories $\mathrm{G}$ and $\mathrm{H}$ (below $1100{ }^{\circ} \mathrm{C}$ ) also fits this second equation. The scatter between laboratories is mostly confined, or nearly so, between the arbitrary limits \pm 10 percent viscosity in poises used by H. R. Lillie ${ }^{7}$ in his analysis of similar measurements. Also shown in figure 6 are the $\pm 5{ }^{\circ} \mathrm{C}$ limits which at $1400{ }^{\circ} \mathrm{C}$ represents a $\pm 0.015 \mathrm{log}$ viscosity $( \pm 3.5$ percent viscosity) and at $600{ }^{\circ} \mathrm{C}$ represents about $\pm 0.2 \mathrm{log}$ viscosity $( \pm 50$ percent viscosity). About 90 percent of the observed points of the participating laboratories fall between these two limits.

The observed values of log viscosity of each laboratory were plotted against the function of temperature 4236/ T'-266 (derived from the combined data points of Laboratories A through E) and are shown in figure 7 . Most of the experimental points submitted by the participating laboratories are seen to fall on a straight line having a slope of unity [2]. The portion of the curve within the dashed rectangle has been expanded and plotted on the right. This range $(\log 2$ to $\log 4)$ is the one in which most viscosity measurements are made since these temperatures are most critical in the melting, fining, and forming of glass.

At the beginning of this program only three participating laboratories ( $\mathrm{A}, \mathrm{B}$, and $\mathrm{C}$ ) made viscosity measurements by the fiber elongation method. These results (down to $560{ }^{\circ} \mathrm{C}$ ) were included in the calculations of the constants for the final equation. Since then, Laboratory $\mathrm{C}$ has sent in one more determination and Laboratory $\mathrm{D}$ has made numerous determinations, covering the range 530 to $700{ }^{\circ} \mathrm{C}$,

${ }^{7}$ H. R. Lillie, Report No. R-163, April 15, 1954, American Ceramic Society Glass Division Standard Glasses, "Test Results from Several Laboratories." Corning Glass Works, Corning, N.Y. 


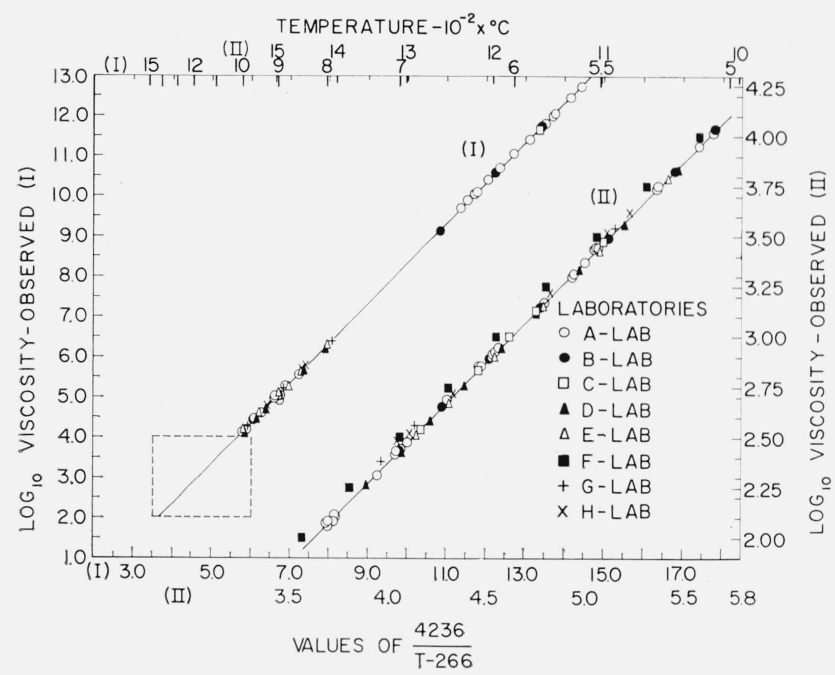

Figure 7. Observed values of log viscosity plotted against the function of temperature $\frac{4236}{\mathrm{~T}{ }^{\circ} \mathrm{C}-266}$.

by a beam bending test. These additional determinations (see below) agree very well with the measurements made by Laboratories $\mathrm{A}, \mathrm{B}$, and $\mathrm{C}$ and would not significantly affect the constants of the final equation if calculated over again.

Laboratory C: (Fiber elongation method)

$\log \eta=12.97$ at $556.3{ }^{\circ} \mathrm{C}$ (No holding time given)

Laboratory D : ${ }^{8}$ (Beam-bending method)

$\log \eta=14.367$ at $530.0^{\circ} \mathrm{C}$ (No holding time given)

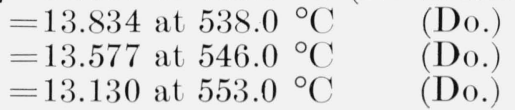

\subsection{Softening, Annealing, and Strain Points}

These empirical points were determined by five participating laboratories with an additional two laboratories determining only the softening point. The definition of these points and method of determining them are given in the ASTM Standards $[11,13]$. The results are shown in table 10 .

TABLE 10. Softening, annealing, and strain points of standard glass No. 710 by participating laboratories

\begin{tabular}{|c|c|c|c|c|c|c|c|c|}
\hline & \multicolumn{8}{|c|}{ Temperature, ${ }^{\circ} \mathrm{C}$} \\
\hline & \multicolumn{8}{|c|}{ Laboratories } \\
\hline & A & B & $\mathrm{D}$ & $\mathrm{E}$ & $\mathrm{F}$ & I & J & Avg \\
\hline Softening pt_- & 727 & 723 & 721 & 721 & 723 & 725 & 727 & 724 \\
\hline Annealing pt & 546 & & 544 & 546 & & 545 & 547 & 546 \\
\hline Strain pt_-_- & 503 & & 501 & 504 & & 505 & 508 & 504 \\
\hline
\end{tabular}

${ }^{8}$ Other low-temperature viscosity measurements on this glass have been published in a paper by H. E. Hagy [12].

\section{Summary}

(1) The National Bureau of Standards has established a viscosity standard for glass, No. 710 (Soda-Lime-Silica). ${ }^{9}$

(2) Viscosity measurements have been made on this glass by eight participating laboratories between 520 and $1450{ }^{\circ} \mathrm{C}$, using the rotating cylinder and fiber elongation methods.

(3) A viscosity-temperature curve was determined from these measurements by fitting the data points to the Fulcher equation by the method of least squares.

(4) The softening, annealing, and strain points of this glass have been determined by seven of the participating laboratories.

The authors acknowledge the interest taken by C. H. Hahner in initiating and directing this program and F. W. Glaze (retired) for his assistance in the calibration work and preliminary calculations. The authors also express their sincerest thanks to all the participating laboratories for their cooperation in making viscosity measurements on this glass.

\section{References}

[1] An improved refractometer, NBS Tech. News Bull. 37, 135 (1953); 38, 63 (1954).

[2] Proceedings of the Society of Glass Technology. Report by the Physical Properties Committee of the Society of Glass Technology, XI, pp. 58-104 (1956).

[3] J. O'M. Bockris and D.C. Lowe, An electromagnetic viscometer for molten silicates at temperatures up to $1800{ }^{\circ} \mathrm{C}$, J. Sci. Instr. 30, 403 (1953).

[4] a. H. R. Lillie, High-temperature viscosities of sodasilica glasses, J. Am. Ceram. Soc. 22, No. 11, 367 (1939).

b. H. R. Lillie, Measurement of absolute viscosity by use of concentric cylinders, J. Am. Ceram. Soc. 12, No. $8,505(1929)$.

c. H. R. Lillie, Viscosity measurements in glass, J. Am. Ceram. Soc. 12, No. 8, 516 (1929).

d. H. R. Lillie, Viscosity of glass between strain point and melting temperature, J. Am. Ceram. Soc. 14, No. 7, 502 (1931).

[5] H. A. Robinson and C. A. Peterson, Viscosity of recent container glass, J. Am. Ceram. Soc. 27, No. 5, 129 (1944).

[6] E. Hatschek, The viscosity of liquids, p. 31, G. Bell \& Sons, Ltd., London, 1928.

[7] J. P. Poole, Improved apparatus for measuring viscosity of glasses in annealing range of temperature, J. Am. Ceram. Soc. 32, No. 7, 215 (1949).

[8] F. H. Norton, Measuring viscosity of glass, Glass Ind. 16, No. 5, 143 (1935).

[9] J. Boow and W. E. S. Turner, Viscosity and Working Characteristics of Glasses; I. Viscosity of Some Commercial Giasses at Temperatures Between $500{ }^{\circ} \mathrm{C}-$ $1400{ }^{\circ} \mathrm{C}$, J. Soc. Glass Tech. 26, No. 117, 215 (1942).

[10] W. K. Lewis, L. Squire and G. Broughton, Industrial Chemistry of Colloidal and Amorphous Materials, p. 24 Macmillan Co., New York, 1942.

[11] ASTM Standards, 1961; "Softening Point of Glass" ASTM Designation: C338-57, pp.1695-698.

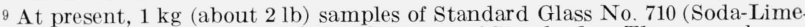
Silica) are available from the National Bureau of Standards. These samples are Silica) are available from the
rectangular-shaped bars $(5 \times 7.5 \times 10 \mathrm{~cm})$ and may be purchased for $\$ 40.00$. 
[12] H. E. Hagy, Experimental evaluation of beam-bending method of determining glass viscosities in the range $10^{8}$ to $10^{15}$ poises, J. Am. Ceram. Soc. 46, No. 2, 93 (1963).

[13] ASTM Standards, 1961, Annealing Point and Strain Point of Glass ASTM Designation C336-54T, pp. $645-650$.

[14] R. L. Tiede, Improved apparatus for rapid measurement of viscosity of glass at high temperatures, J. Am. Ceram. Soc. 42, No. 11, 537 (1959).

[15] H. R. Lillie, Viscosity-Time-Temperature Relations in Glass at Annealing Temperatures, J. Am. Ceram. Soc. 16, No. 12, 619 (1933)

[16] W. H. Otto, Compaction Effects in Glass Fibers, J. Am. Ceram. Soc. 44, No. 2, 68 (1961).
[17] A. Q. Tool, Viscosity and the extraordinary heat effects in glass, J. Res. NBS 3\%, 73-90 (1946) RP1730; Ceram. Abstr. 30, 7 (1947).

[18] G. S. Fulcher, Analysis of Recent Measurements of Viscosity of Glasses, J. Am. Ceram. Soc. 8, No. 6, 339 (1925).

[19] B. P. Dudding, Errors in the Measurements of Viscosity of Glass, Proc. Third Intern. Congr. on Glass, pp. 296-317, Associazione Nazionale Degli Industriali Del Vetro, Rome (1954). 